\title{
Environmental quality for patients with dementia
}

\author{
Peter Bowie
}

For centuries the conditions existing in institutions have been a cause of concern. Accompanying this has been a drive to improve the quality of care in such places. Until the second half of this century younger patients constituted the majority of the mentally ill residing in institutions. Now the balance has shifted and considerable numbers of elderly people, particularly those suffering from dementia, are residing in institutions (hospitals, nursing and residential homes). Perhaps never before has the question "What makes a good environment for the demented?" been so important.

\section{Historical perspectives}

There have been many descriptive accounts of institutions but relatively few have stimulated research or induced significant change in the institutional system over the last three decades. One of the first accounts was made by a psychiatrist, Russell Barton (1959), who described a condition - institutional neurosis - which he considered to be a product of the institution and not of the original illness. The condition was characterised by apathy, lack of initiative, loss of interest in the outside world, submissiveness, and resignation. Patients with the condition took no interest in the future and their personal habits and standards deteriorated. Barton chose to focus on seven clusters of factors in the mental hospital environment which he believed caused the condition (Box 1). He pointed out that not all residents of institutions develop institutional neurosis, and that some people outside hospital may do so. However, his critique of institutions was made so clearly that it provided a framework for change and research.

Working separately to Barton, Goffman (1961) described the 'total institution' as "a place of residence and work where a large number of likesituated individuals, cut off from the wider society for an appreciable period of time, together lead an enclosed, formally administered round of life". He identified four main characteristics that distinguish total institutions:

Batch living - all aspects of daily living are conducted in the same place and under the same single authority, with each resident's daily living activity being carried out in the immediate company of a large batch of others, all of whom are treated alike and required to do the same things. Binary management - two different social and cultural worlds develop, a staff world and a residents world.

Inmate role - a process of role-stripping that renders the individual incapable of normal living when he returns to the community. The individual is reduced from a person with many roles to a cypher with one. This Goffman saw as being due to the resident being cut off from his past life, given uniform clothing, and the restriction or confiscation of personal possessions.

Institutional perspective - the various enforced activities are brought together in a single rational plan purportedly to fulfil the official aims of the institution.

Goffman then describes the behaviours or coping styles that a resident of an institution adopts in order to survive "these attacks on his personality". He suggested four styles of adjustment:

(i) Withdrawal - the resident cuts himself off from contact.

(ii) Intransigence - the resident fights the system.

(iii) Colonisation - the resident pays lip-service to the system awaiting the day of independence.

(iv) Conversion - the resident accepts the institution's view of himself.

The fourth is more 'personal extinction' than survival, but was highlighted by Goffman as the

Dr Bowie is a Consultant in old age psychiatry at High Royds Hospital, Menston, Ilkley, LS29 6AQ. He has carried out research on ward environment and the behaviour of demented patients at the University of Leeds. 


\section{Box 1 Factors causing institutional neurosis}

(i) Loss of contact with the outside world: caused by locked doors, poor facilities for visitors, difficulty in writing letters, and inability to make ordinary social relationships.

(ii) Enforced idleness: due to ward routines, lack of activity or meaningful work.

(iii) Bossiness of medical and nursing staff: reflected in authoritarian attitudes, petty tyranny and bullying.

(iv) Loss of personal friends, personal possessions, and personal events: these are replaced by institutional possessions and events.

(v) Drugs: the use of sedative drugs to produce apathy and make patients easier to manage.

(vi) Impoverished ward atmosphere: poor furniture, decoration and lighting, dirt, noise, smell, and the appearance of other patients all produce a general environment of drabness and depression.

(vii) Loss of prospects: the difficulties of taking up the patterns of family and work life again, problems of accommodation and making friends, and fears of loneliness in the outside world.

only adjustment acceptable to the authorities of the institution. Attempts by the resident to behave differently would be interpreted as noncooperation and be used to justify further treatment and detention. The end products of this process are apathy, submissiveness, deviant behaviours such as scavenging, hoarding small articles, and other behaviours reflecting a deterioration of self-care skills and personal standards.

Goffman's picture of bureaucratisation and depersonalisation, together with the substitution of institutional values for personal human values, was powerful and accurate. It has been a focal point of subsequent research and organisational change in health services and institutional care.

Townsend (1962) drew attention to residential institutions and homes for old people. He noted that the elderly residents appeared robbed of all initiative, were dressed in shapeless suits, and had adopted a behavioural pattern of stoic resignation. Like Barton and Goffman, Townsend found evidence of lack of privacy, loss of meaningful occupation, inability to form new relationships, and the collapse of self-determination.
Similarly Robb (1967) exposed practices in institutions for the elderly and the elderly mentally ill. The report gave alarming accounts of conditions endured by elderly patients including rudeness, rough handling, undignified use of commodes, and neglect of cleanliness. As might be expected the behaviour of the patients seems similar to the accounts of apathy and resignation already cited.

These accounts have been followed by quantitative research which has tended to divide the environment into physical and social components.

\section{The physical environment}

From the many aspects of the physical environment, researchers have concentrated on five: physical design, furnishings, state of repair, recreational materials, and reality orientation.

\section{Physical design}

Using behavioural mapping Ittelson et al (1970) found that isolated, passive patient behaviour is directly proportional to bedroom size. In addition where there was a policy to encourage patients to engage in off-the-ward activity and they were discouraged from using their bedrooms, less isolated, passive behaviour occurred in the bedrooms. These effects of ward and institutional policy may of course have been an explanation for the first finding, rather than room size.

Harris et al (1976) studied the location and interactions of old people living in eight residential homes. During six hours observation in each home, events, sitting space, size and layout were recorded. They found that sitting spaces in peripheral locations tended to be underused; chairs arranged around the walls were not conducive to verbal interaction; lengthy corridors appeared to discourage resident mobility; and rooms designated as 'bed-sitting' were used as bedrooms only.

\section{Furnishings}

Sommer \& Ross (1958) evaluated the effects of furnishings on residents' behaviour, in a psychiatric ward for the elderly, . They rearranged the dayroom chairs into small groups around tables rather than around the walls and demonstrated an increase in both brief and sustained interactions made by the patients. However, staff brought in magazines which were placed on the tables and an occupational therapist began to work on the ward, which may have confounded the results. 
Holahan (1972) attempted to avoid such confounding factors by manipulating seating patterns in an experimental dayroom. This well designed experiment suggested that seating arrangements have a powerful influence over social behaviour, arrangements around small tables having a positive effect.

\section{State of repair}

No studies have specifically investigated the state of repair (quality of decorations, furnishings, and the state of the walls, ceilings, and floors) and its' effects on the residents' behaviour separately. However, some studies such as Holahan \& Saegert (1973) have included this as one aspect of large scale change.

\section{Recreational materials}

McClannahan \& Risley (1975) reported a study of elderly nursing home residents whose behaviour was assessed before and after an intervention providing recreational materials and equipment. They found that interactive behaviour increased significantly when recreational materials were provided and the residents were prompted to use them. But when materials were only available on request, social behaviour was similar to when the materials or activity were not available.

McCormack \& Whitehead (1981) examined the effect of introducing individual and group activities on a long-stay geriatric ward. The study was divided into five periods: baseline, individual activities, withdrawal of activities, group activities, and withdrawal of group activities. They found that provision of activities led to an increase in patient engagement and that group activities had a greater effect. The increased social engagement did not continue after the activity sessions were withdrawn. This may reflect a need for patients to be organised into activity. Alternatively, the inappropriateness of the activities provided to this elderly client group (dice and ball-throwing games!) may have been a factor.

\section{Reality orientation}

Reality orientation (RO) has been comprehensively reviewed by Holden \& Woods (1985). There are two major components: (i) 24-hour reality orientation where every interaction with the patient is used to convey current information; and (ii) reality orientation sessions organised on a group basis. In addition reality orientation can be reinforced by orientation cues such as clocks, sign posts, colour coded doors, and date or weather boards. A number of evaluations of reality orientation have been carried out, concluding that it is effective in modifying verbal orientation in patients with mild or moderate dementia. However, behavioural change as a consequence of reality orientation has not been demonstrated (Hanley et al, 1981). The effectiveness of providing cues alone has not been studied.

\section{The social environment}

The social environment of a ward or residential setting has been given a range of similar definitions from researchers. Most have agreed that the term encompasses care practices operating within the establishment. At one extreme these practices are client orientated and at the other, institution orientated. Investigation of the effects of institutional environments on the behaviour or function of the residents was pioneered by King and Wing \& Brown in the 1960s.

King \& Raynes developed a scale to assess management practices (1968). This and subsequent scales were developed when there was growing awareness that institutionalisation did not always lead to a deterioration in the behaviour of the residents - and it was therefore important to establish what factors distinguished institutions where deterioration occurred from those where the residents improved. King et al (1971) described the scale as having four dimensions: rigidity of routine, block treatment, depersonalisation, and social distance (Box 2).

During a similar period Wing \& Brown (1961; 1970) carried out comparative surveys of three psychiatric hospitals to investigate the effects of institutionalisation on the behaviour and functioning of long-term residents suffering from schizophrenia.

Two aspects of institutional practice were assessed. Firstly, the authors developed a 'ward restrictiveness scale' which assessed the extent to which patients' movements and actions were restricted by the established ward practices. Secondly, they developed an inventory of patients' possessions. They also developed six indices of the patient's clinical state, and demonstrated a strong relationship between patients' social withdrawal and the ward restrictiveness score. There was significant correlation between personal possessions and clinical state; few possessions was associated with social withdrawal, flatness of affect, poverty of speech, socially embarrassing behaviour, unfavourable attitude to discharge, and length of stay. All these associations were confirmed when the survey was repeated in 1964. 
The more recent work of Willcocks et al (1987), covering both physical and social aspects of the environment, deserves mention. They surveyed one hundred institutions for the elderly. These institutions were residential homes owned and run by local authorities and were selected after a postal survey of approximately 1000 residential homes. The survey collected data on size (number of beds), layout and design, internal amenities and aids. In addition residents and staff were interviewed and asked to complete questionnaires regarding policies, satisfaction, and psychological well-being. The authors found that the larger homes offered more amenities and that the residents of these homes were better adjusted, although they were more dissatisfied with the staff.

Willcocks and colleagues are one of only a few groups researching the care of the elderly in institutions. There has been even less attention paid to the elderly suffering from dementia - a situation which stimulated my own investigation into the relationship between the environment and the behaviour of demented patients. One of the few studies of a demented population evaluated the effect of changing the care setting from a traditional mental hospital to an independently run unit (a domus) with a defined philosophy of care (Dean et al, 1993). This study suggested that, in terms of quality of interpersonal interactions, the domus philosophy provided greatly improved standards of social care.

With or without research evidence, to improve the quality of an environment one must be aware of which aspects to consider and have a means of measuring the quality of those aspects.

Box 2 Four dimensions of care practices

(i) Rigidity of routine refers to inflexible practices which do not vary from day to day and limit the resident's choice.

(ii) Block treatment refers to activities which are carried out with all residents treated alike and required to do things at the same time.

(iii) Depersonalisation refers to practices which reflect the resident's opportunity to have possessions and to experience personal events (both collective and private).

(iv) Social distance refers to practices that reflect a division between the worlds of staff and residents.

\section{Measuring environmental quality}

One role of the Health Advisory Service is to assess and monitor the quality of care and the environment in long-stay institutions. Almost invariably this assessment is subjective in nature and dependent on the personal views of the assessing team. Subjective assessment is also carried out by health professionals, service managers and possibly purchasing authorities when service development or reprovision schemes are planned. It is not therefore surprising that deficiencies in the care environment continue to be relatively commonplace (Mountain \& Bowie, in press). The use of more objective measurement could be advantageous in increasing awareness and promoting change.

Measuring environments is not without its pitfalls. Firstly, there are problems with defining some aspects of the environment. Barton (1959) for example, included decoration, lighting, cleanliness, noise and smell in his definition of ward atmosphere. Many others have regarded these items as part of the physical environment - the ward condition. Secondly, in some areas there are problems of inter-observer reliability caused by individual taste, this can be illustrated by considering the physical attractiveness of room decorations. What is pleasing to the eye of one person may not be to the next. Thirdly, the client group residing in the environment may influence measurement. Some aspects of the environment, for example space availability, can be measured without consideration of the client group. Other aspects, particularly social aspects such as the assessment of care practices may require instruments specific to defined client groups.

Many researchers have attempted to assess environmental quality. Often assessment has been limited to just one or two aspects of the environment. The assessment of institutional care practices has been one of the most frequently measured aspects. Several instruments have been developed which although having common themes, have been developed for use with specific client groups. For use with chronic psychotic patients in a number of different settings instruments have been devised by Wing \& Brown (1961), Wykes et al (1982), and by Lavender (1984). King et al (1971), and Raynes et al (1979) developed similar scales for use with learning disabled children. A scale to assess the quality of the physical environment was also developed by Lavender (1984), as part of an assessment package for rehabilitation wards. In 


\section{Box 3 Sub-scales of the MEAP}

The Physical and Architectural Features Checklist has eight sub-scales covering community accessibility, physical amenities, social and recreational aids, prosthetic aids, orientational aids, safety features, staff facilities, and space availability.

The Policy and Programme Information Form has nine subscales which cover various admission criteria, resident involvement in policy making, provision for privacy, and availability of various services and activities.

The Resident and Staff Information Form has nine sub-scales which cover the training and demographic background of staff and residents, assessment of resident dependency and activities, and the use of health and daily living services and of social or recreational activities.

The Sheltered Care Environment Scale is an attempt to assess the social climate of the facility. There are seven sub-scales covering resident cohesion, conflict, independence, self-exploration, organisation of the facility, resident influence and physical comfort.

The final part of the MEAP is referred to as Rating Scales and consists of four unrelated sub-scales assessing physical attractiveness of the building, environmental diversity, resident functioning, and staff functioning.

addition to this aspect of the environment and care practices he developed scales to assess social activities, and contact with the community.

One of the most detailed and comprehensive instruments for assessing environmental quality is the Multiphasic Environmental Assessment Procedure (MEAP; Moos \& Lemke, 1979). The MEAP was designed to describe and evaluate the settings in which elderly people reside. The MEAP is divided into five parts, which can be used separately - the Physical and Architectural Features Checklist; the Policy and Programme Information Form; the Resident and Staff Resources Dimensions; the Sheltered Care Environment Scale Dimensions, and Rating Scale Dimensions. Each part comprises a number of dimensions or sub-scales which may be used independently (Box 3 ).

There are some criticisms of the MEAP - a lack of validity and reliability studies, a strange mix of items in some subscales, the requirement for residents to act as their own advocates, a loss of discriminatory power by the use of 1 or 0 scoring in places, and an incorporation of culture linked items in some sub-scales. However, it is by far the most comprehensive environmental assessment instrument available and has successfully been used in Britain (Benjamin \& Spector, 1990).

The need for self-advocacy and the lack of assessment of RO by the MEAP impedes its usefulness when assessing environments for the confused elderly. This led to the development of a specific package - Rating Scales for the Assessment of Environments for the Confused Elderly (Bowie et al, 1992). This package is made up of six rating scales covering institutional care practices, social/ recreational facilities and activities, $R O$ cues, ward condition, and ward size. One scale is a questionnaire to be completed by care staff, the others are based on observer assessment. While this package has been specifically developed for use with the confused elderly it is not comprehensive. For a more comprehensive assessment I would suggest combining this package with some sub-scales of the MEAP.

\section{The effects of the environment}

From the early descriptions of Barton and Goffman it is clear that certain behaviours exhibited by residents were linked with environmental conditions. There is no reason to assume that the confused elderly are not also affected by their living environment and display certain behaviours in association with environmental quality. To investigate this hypothesis Mountain \& Bowie (in press) carried out a survey of long-stay wards for the confused elderly. Seven wards with a range of environmental quality were selected for further study. Patient behaviour was then assessed using direct observation (Bowie \& Mountain, 1993). Almost 114 hours of observed patient behaviour was recorded and categorised into seven categories - self care, social engagement, receipt of care, abnormal motor activity, inappropriate behaviour, antisocial behaviour, and neutral behaviour (doing nothing). The project was designed so that wards differing in one aspect of environmental quality could be compared.

Over $50 \%$ of time is accounted for by neutral behaviour. In other words, for more than half of the waking day the patients are doing nothing at all (Table 1). These findings are similar to those found in residential settings (Godlove et al, 1982).

By comparing wards which differed on one aspect of the environment, the following associations 
between environmental quality and the behaviour of demented patients were found.

(i) Poor quality (institutional) care practices were associated with significantly more abnormal motor activity and inappropriate behaviour.

(ii) High social and recreational input was associated with more social engagement from the patients. It was also associated with more abnormal motor activity and inappropriate behaviour, but less time was spent doing nothing.

(iii) Poor quality RO cues were associated with more inappropriate behaviour. Ward condition and size were not associated with any differences in patient behaviour.

These findings would tentatively suggest that the quality of care practices, social/recreational facilities and activities, and RO cues might have an effect on resident behaviour, although a causal relationship cannot be assumed. They also suggest that the quality of ward condition and size are less important aspects of the environment. With regard to social and recreational input, high quality here is associated with both desirable and undesirable behaviours - it may be that an extreme of high quality provision not only improves socialisation but leads to over-stimulation and the genesis of restless and inappropriate behaviour.

\section{Implications for clinical} practice

There is a great need for improvements in the quality of long-term care for the elderly confused patient. This needs to be addressed by several professions and statutory agencies. The picture, however, is further complicated by the massive switch of long-term care from NHS provision to the private sector during the 1980s - the NHS now only provides around $10 \%$ of the long-term care beds in the UK (Ebrahim et al, 1993). There is no doubt that problems within hospital provision are equally commonplace in local authority and private homes (Murphy, 1992).

Much of the long-term care delivered to elderly demented patients is given by unqualified staff, sometimes under the guidance of RMN nurses, depending on the setting. There are obvious implications for nurse and care staff training and the provision of continuing education.

Staff working on wards (or indeed in residential or nursing homes) for the elderly confused should

\begin{tabular}{|lc|}
\hline $\begin{array}{l}\text { Table 1. Average amount of time exhibiting each } \\
\text { behaviour }\end{array}$ \\
\hline Behaviour & $\begin{array}{l}\text { Proportion of } \\
\text { waking hours }\end{array}$ \\
\hline & $8.6 \%$ \\
Self-care & $5.5 \%$ \\
Social engagements & $5.3 \%$ \\
Receipt of care & $18.7 \%$ \\
Motor activity & $0.2 \%$ \\
Anti-social & $11.3 \%$ \\
Inappropriate & $56.5 \%$ \\
Neutral & \\
\hline
\end{tabular}

be encouraged to re-examine their care practices and the provision of social-recreational materials. The care practices of staff have been demonstrated as the distinguishing features between excellent and ordinary nursing homes (Andersen, 1987; Clark \& Bowling, 1990). Addressing care practices may require some retraining, but social and recreational activity could be improved with relative ease, as could the provision of clear and accurate $\mathrm{RO}$ cues.

Many staff, including consultants, senior nurse managers and inspectorates, regularly visit these wards and residential/nursing homes. The patients are generally incapable of self-advocacy; it is therefore our duty to be vigilant on their behalf. We need to point out deficiencies in the environment and help promote an atmosphere of change towards a resident orientated regime. The reprovision of services into new, purpose built accommodation will only improve the physical aspects of the environment and these are probably less important than the aspects of care practices and social activity. The provision of new buildings may provide us with an opportunity to change other aspects of the environment, but we should not forget that significant improvements in quality can be made without the provision of new facilities.

\section{References}

Anderson, B. R. (1987) What makes excellent nursing homes different from ordinary nursing homes? Danish Medical Bulletin, 5, 7-11.

Barton, R. (1959) Institutional Neurosis. Bristol: Wright.

Benjamin, L. C. \& Spector, J. (1990) Environments for the dementing. International Journal of Geriatric Psychiatry, 5, 15-24.

Bowie, P., Mountain, G. \& Clayden, D. (1992) Assessing the environmental quality of long-stay wards for the confused elderly. International Journal of Geriatric Psychiatry, 7, 95-104.

__ \& - (1993) Using direct observation to record the behaviour of long-stay patients with dementia. International Journal of Geriatric Psychiatry, 8, 857-864.

Clark, P. \& Bowling, A. (1990) Quality of everyday life in long stay institutions for the elderly. An observational study of long stay hospital and nursing home care. Social Science and Medicine, 30, 201-210. 
Dean, R., Proudfoot, R. \& Lindesay, J. (1993) The quality of interactions schedule (QUIS): development, reliability and use in the evaluation of two domus units. International Journal of Geriatric Psychiatry, 8, 819-826.

Ebrahim, S., Wallis, C., Brittis, S., et al (1993) Long term care for elderly people. Quality in Health Care, 2, 198-203.

Godlove, C., Richard, L. \& Rodwell, G. (1982) Time for Action. Social Services Monograph: Research in Practice. Joint Unit for Social Services Research and Community Care, Sheffield University.

Goffman, E. (1961) Asylums: Essays on the Social Situation of Mental Patients and other Inmates. London: Penguin.

Harris, H., Lipman, A. \& Slater, R. (1976) Architectural design: the spatial location and interactions of old people. Gerontology, 23, 390-400.

Holahan, C. J. (1972) Seating patterns and patient behaviour in an experimental day room. Journal of Abnormal Psychology. 80, 115-124.

- \& Saegert, S. (1973) Behavioural and attitudinal effects of large scale variation in the physical environment of psychiatric wards. Journal of Abnormal Psychology, 82, 454462.

Holden, U. P. \& Woods, R. T. (1985) Reality Orientation; Psychological Approaches to the Confused Elderly. Edinburgh: Churchill Livingstone.

Hanley, I. G., McGuire, R. J. \& Boyd, W. D. (1981) Reality orientation and dementia: a controlled trial of two approaches. British Journal of Psychiatry, 138, 10-14

Ittleson, W. H., Rivlin, L. G. \& Prohansky, H. M. (1970) The use of behavioural maps in behavioural psychology. In Environmental Psychology. Man and His Physical Setting (eds H. M. Prohansky, W. H. Ittelson \& L.G. Rivlin), pp. 658-668. New York: Holt, Rinehart and Winston.

King, R. D. \& Raynes, N. V. (1968) An operational measure of inmate management in residential institutions. Social Science and Medicine, 2, 41-53.

- - \& Tizard, J. (1971) Patterns of Residential Care. London: Routledge and Kegan Paul.

Lavender, A. (1984) Evaluation and Change in Settings for the Long Term Psychologically Handicapped. PhD Thesis, University of London, Kings College Medical School.

McClannahan, L. E. \& Risley, T. R. (1975) Design of living environments for nursing home residents: increasing participation in recreational activities. Journal of Applied Behaviour Analysis, 8, 261-268.

McCormack, O. \& Whitehead, A. (1981) Effect of providing recreational activities on the engagement level of long-stay geriatric patients. Age and Ageing, 10, 287-291.

Moos, R. H. \& Lemke, S. (1979) The Multiphasic Environmental Assessment Procedure (MEAP): Preliminary Manual. Stanford University Medical Center, Palo Alto: Social Ecology Laboratory,

Mountain, G. \& Bowie, P. (In press) The quality of long term care for dementia - a survey of ward environments. International Journal of Geriatric Psychiatry.

Murphy, E. (1992) Quality assurance in residential care. International Journal of Geriatric Psychiatry, 7, 695-697.

Raynes, N. V., Pratt, M. W. \& Roses, S. (1979) Organisational Structure and the Care of the Mentally Retarded. London: Croom Helm.

Robb, B. (1967) Sans Everything: a Case to Answer. London: Nelson.

Sommer, R. \& Ross, H. (1958) Social interaction on a geriatric ward. International Journal of Social Psychiatry, 4, 128-133.

Townsend, P. (1962) The Last Refuge: a Survey of Residential Institutions and Homes for the Aged in England and Wales. London: Routledge and Kegan Paul.

Willcocks, D., Peace, S. \& Kellaher, L. (1987) Private Lives In Public Places. London: Tavistock.

Wing, J. W. \& Brown, G. W. (1961) Social treatment of schizophrenia: a comparative survey of three mental hospitals. Journal of Mental Science, 107, 847-861.
_ \& - (1970) Institutionalism and Schizophrenia. Cambridge: Cambridge University Press.

Wykes, T., Sturt, E. \& Creer, C. (1982) Practices of day and residential units in relation to the social behaviour of attenders. In Long-Term Community Care: Experience in a London Borough (ed. J. K. Wing) pp. 15-28. Psychological Medicine Monograph Supplement 2.

\section{Multiple choice questions}

1 Barton described the following factors in the causation of 'institutional neurosis':

a Loss of possessions and personal events

b Social distance between staff and patients

c Enforced idleness

d drugs

2 According to Goffman the resident of an institution adjusts by adopting:
a Aimless wandering
b Excitement
c Conversion
d Intransigence

3. On an average day a demented patient in longterm care:

a is antisocial for more than $10 \%$ of the time

b spends one third of his time in meaningful activity

c spends most of the time doing nothing

$d$ is socially engaged for less than $10 \%$ of the time

4 High quality provision of social/recreational material for demented patients has been associated with:

a increased social behaviour

b no difference in the time spent doing nothing

c more abnormal motor activity

d more antisocial behaviour

5 Institutional styles of care practice:

a include restricting patients' possessions

b are associated with more undesirable behaviours from the patients

c are only found in large asylums

d can be abolished simply by providing new purpose built facilities

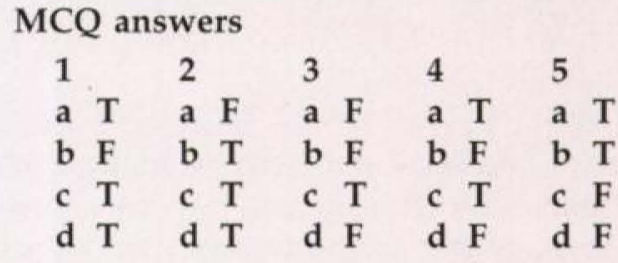

